\title{
EDITORIAL
}

\section{Los disruptores y la endocrinología}

$\mathrm{F}$ ue en el consenso realizado en 1991 en la población de Wingspread casa cercana a Racine, en el estado de Wisconsin, sede de estudios ambientales, cuando se acuñó el término de disruptor endocrino para describir el efecto que tenían ciertas sustancias exógenas para interferir con algunas hormonas en el organismo, causando alteración de la homeostasis, reproducción, desarrollo y/o conducta de un individuo ${ }^{(1)}$.

Pero solo fue en 1993 cuando aparecieron las primeras publicaciones científicas, estableciendo que algunas sustancias difundidas en el ambiente alteran o bloquean los mecanismos endocrinos. Estos pueden actuar como agonistas o antagonistas de los receptores de estrógenos, andrógenos, hormonas tiroideas e insulina, entre otras ${ }^{(2)}$.

Uno de los problemas de debate en relación con estas sustancias es que no tienen un efecto dosis-respuesta monotónica (mayor estímulo mayor respuesta) comprobado de manera experimental, sino que presentan una respuesta llamada en U que aún en dosis bajas podría presentar efectos tóxicos.

Sus efectos se pueden presentar por mecanismos genómicos y no genómicos, vía receptor o independiente de ellos, actuando especialmente sobre los receptores nucleares (estrógenos, andrógenos, glucocorticoides, progesterona, mineralocorticoides, hormonas tiroideas), o como antagonistas en los sistemas hormonales, impidiendo la acción de la hormona endógena, o también activando la cantidad necesaria para su acción o para su degradación. Esto ha abierto un campo importante dentro del marco de la endocrinología experimental.

Son muchos los disruptores endocrinos que se han identificado hasta el momento, los cuales están relacionados con lubricantes, pinturas, plásticos, herbicidas, papeles térmicos, insecticidas, protectores solares, etc.

Uno de los más importantes es el llamado Bisfenol A (BPA, por sus iniciales en inglés) y con el cual se han llevado a cabo estudios experimentales, éste se encuentra en los plásticos, resinas epóxicas y papeles térmicos, especialmente, y por encontrarse en el plástico de envases como botellas de bebidas, cajas de almacenamiento de alimentos, la posibilidad de producir efectos tóxicos es muy alta. Se han descrito alteraciones prostáticas, mamarias, de la conducta cerebral, desarrollo reproductivo y del sistema inmune ${ }^{(3)}$.

Otra parte muy importante es el efecto de estos disruptores sobre el tracto reproductivo, desarrollo puberal, falla ovárica primaria, ovario poliquístico, obesidad y diabetes.

En relación con la diabetes y la obesidad, estudios transversales han mostrado una relación, lo mismo que con enfermedades cardiovasculares, sobre todo con sustancias altamente resistentes a la degradación, debido a su naturaleza lipofílica, conocidos como polulantes orgánicos persistentes (POP), de los cuales los más comunes son las dioxinas, los pesticidas organoclorados y los derivados del DDT (diclorodifenil tricloroetano).

Quiero destacar el capítulo sobre este tema escrito por las doctoras Maritza Pérez y Amanda Páez, miembros de nuestra asociación, en el libro FISIOLOGÍA ENDOCRINA, publicado recientemente por la Asociación Colombiana de Endocrinología, Diabetes y Metabolismo, en colaboración con la editorial Manual Moderno ${ }^{(4)}$.

En Colombia estamos frente al debate de la fumigación de sustancias ilícitas mediante el uso de sustancias derivadas del glifosato, que han demostrado que pueden producir algunos tipos de cáncer y, dentro del sistema endocrino, alteración en la producción y acción de la progesterona, debate no terminado y en el cual están involucradas varias organizaciones internacionales.

El conocimiento de los disruptores endocrinos abre un nuevo capítulo de la endocrinología, con el cual los endocrinólogos no estamos familiarizados, tema de gran impacto no solamente sobre la salud, sino también en el aspecto económico, de calidad de vida y político, haciendo un llamado a las entidades formadoras de profesionales de la salud para que lo involucren dentro de sus programas académicos.

\section{Enrique Ardila \\ Editor, Revista ACE}

\section{Referencias}

1. Diamanti-Karandakis E. Endocrine Disruption Chemicals. An Endocrine Scientific Statement. 2009. 30(4): $293-342$.

2. Vanderbeg LN. Hormones and EDC's : Low Doses and Nonmonotoxicity. Endocr Rev. 2012. 33(3): 378-455.

3. Vanderberg LN. Bisphenol A and the Great Divide : A Review of Controversies in the Field of Endocrine Disruption. Endocr Rev. 2009. $30: 75-95$.

4. Pérez M., Páez. A. Disruptores Endocrinos. En: Fisiología endocrina, Jácome A., Ardila E., Casas lA (eds) Ed. Manual Moderno. Asociación Colombiana de Endocrinología, Diabetes y Metabolismo, Cap. 17, pp. 396-409. Bogotá, 2017. 